\title{
Indução de metabólitos secundários em plântulas de Hypericum brasiliense Choisy crescendo in vitro
}

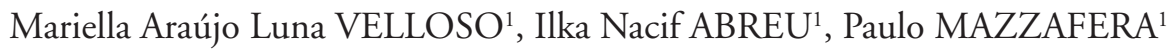 \\ RESUMO \\ A produção de rutina, quercetina, 1,5-diidroxixantona e ácido betulínico foi investigada em plântulas de $H$. brasiliense \\ crescendo in vitro, sob a influência de ácido salićlico, polietilenoglicol, $\mathrm{NaCl}$, 24-epibrassinolídeo, benzotiadiazole (BION), \\ metiljasmonato e concentrações aumentadas de boro e nitrogênio no meio líquido de cultura. As avaliações foram feitas após \\ 5 e 10 dias do início dos tratamentos. Os maiores aumentos de conteúdo foram observados com quercetina para boro e ácido \\ salicílico aos 5 dias, e 24-epibrassinolídeo e BION aos 10 dias.
}

PALAVRAS-CHAVE: Ácido betulínico, Quercetina, Rutina, Xantona.

\section{Induction of secondary metabolites in plantlets of Hypericum brasiliense Choisy in vitro}

\begin{abstract}
The production of rutin, quercetin, 1,5-dihydroxyxanthone and betulinic acid was investigated in plantlets of $H$. brasieliense in vitro, and exposed to salycilic acid, poliethylene glycol, $\mathrm{NaCl}$, 24-epibrassinolide, benzothiadiazole (BION), methyljasmonate and increased concentrations of boron and nitrogen in the liquid culture medium. Evaluations of the contents were carried out after 5 and 10 days of treatments. The highest increase was observed in quercetin in the salycilic acid and B treatments after 5 days of exposure, and in 24-epibrassinolide and BION after 10 days.
\end{abstract}

KEY WORDS: Betulinic acid, Quercetin, Rutin, Xanthone.

\footnotetext{
1 Depto Fisiologia Vegetal, Instituto de Biologia, Unicamp, Caixa Postal 6109, 13083-970, Campinas, SP, Brasil. e-mail: pmazza@unicamp.br
} 


\section{INTRODUÇÃO}

Em extratos de Hypericum brasiliense Choisy foram identificadas xantonas, acilfloroglucinóis, flavonóides e ácido betulínico, que possuem importante potencial farmacológico (Rocha et al., 1994, 1995, 1996; Abreu et al., 2004). Tais compostos são sintetizados a partir de diferentes rotas metabólicas (via do ácido chiquímico e via dos terpenos) e a sua concentração em plantas é influenciada por fatores bióticos e abióticos, tais como hormônios, luz, nutrientes, água, etc. (Dixon \& Paiva, 1995; Croteau et al., 2000).

$\mathrm{O}$ interesse pela fisiologia do estresse e seus efeitos no conteúdo de metabólitos secundários em plantas em parte é explicado por querer se conhecer as possíveis adaptaçôes que poderiam ocorrer no metabolismo desses compostos, maximizando a produção de constituintes ativos de plantas medicinais e condimentares (Dixon \& Paiva, 1995; Verpoorte et al., 1999).

O estresse hídrico (excesso e falta de água) e variaçōes de temperatura causaram alterações na produção de metabólitos secundários em H. brasiliense (Abreu \& Mazzafera, 2005). De modo geral o estresse hídrico aumentou os níveis de todos os metabólitos em questão, especialmente dos flavonóides, enquanto a variação da temperatura influenciou de forma diferenciada os grupos de metabólitos estudados.

Uma das estratégias para estudos sobre o controle metabólico de compostos secundários é o uso da regeneração de plântulas in vitro, através de cultura de brotos. Essa capacidade de regeneração tem sido muito valiosa para a biotecnologia vegetal, sendo possível o cultivo de exemplares mais produtivos em meios otimizados para o crescimento e acúmulo de metabólitos secundários, incluindo o desenvolvimento de culturas de células (Zenk et al., 1977).

Diferentemente dos trabalhos já conduzidos com $H$. perforatum, nos quais foram investigados metabólitos secundários produzidos por órgãos da planta regenerada, como por exemplo folhas em diferentes estádios e raízes (Pasqua et al., 2003; Zobayed et al., 2004), o objetivo do presente estudo foi analisar a variação de metabólitos secundários em plântulas de $H$. brasiliense in vitro na presença de indutores de expressão gênica, como metiljasmonato, brassinoesteróides, ácido salicílico e seu análogo BION (benzothiadiazole), assim como na presença de agentes estresssantes (polietilenoglicol e $\mathrm{NaCl}$ ). Tal estratégia elimina a influência da regeneração, que pode ser mais um fator afetando a produção de compostos do metabolismo secundário. Foram acompanhadas as alterações nos conteúdos de 1,5-diidroxixantona, quercetina, rutina e ácido betulínico (Figura 1), substâncias que tem reconhecida aplicação farmacológica (Abreu et al., 2004).

\section{MATERIAL E MÉTODOS}

Para a implantação dos experimentos, como explantes foram utilizadas plantas adultas de $H$. brasiliense, mantidas em boas condiçōes fisiológicas e fitossanitárias em casa de vegetação. Gemas nodais foram deixadas em água corrente

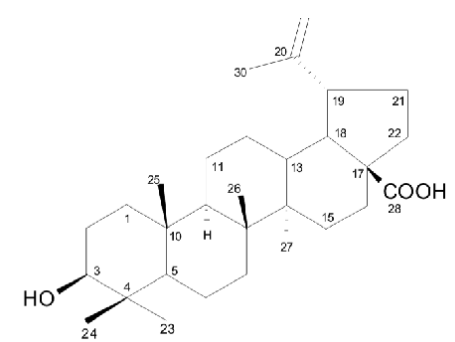

$\bar{e}$ cido Betul'nico<smiles>O=c1c2cccc(O)c2oc2cccc(O)c12</smiles>

1,5-Diidroxixantona<smiles>O=c1c(O)c(-c2ccc(O)c(O)c2)oc2cc(O)cc(O)c12</smiles><smiles>[R4]COc1c(-c2ccc(O)c(O)c2)oc2cc(O)cc(O)c2c1=O</smiles>

Figura 1 - Estruturas químicas do ácido betulínico, rutina, quercetina e 1,5-diidroxixantona. 
por $10 \mathrm{~min}$, depois imersas em etanol $70 \%$ por $30 \mathrm{seg}$ e, em seguida, por 30 min em $20 \%$ de hipoclorito de sódio comercial ( $0,4 \%$ cloro ativo). Em câmara de fluxo laminar, os explantes foram lavados por cinco vezes em $\mathrm{H}_{2} \mathrm{O}$ destilada e autoclavada, excisados e inoculados em meio de cultura. Os explantes foram inoculados em meio de cultura MS (Murashige \& Skoog, 1962) líquido, contendo $3 \%$ de sacarose, $\mathrm{pH}$ ajustado para 5,8 , sem a adição de reguladores. Utilizou-se tubos de ensaio $(25 \times 150 \mathrm{~mm})$, contendo $10 \mathrm{~mL}$ de meio de cultura e pontes de papel de filtro como suporte. Após a inoculação, os tubos foram mantidos em sala de crescimento com temperatura de $25 \pm 1^{\circ} \mathrm{C}$ e fotoperíodo de $16 \mathrm{~h}$, com luz branca fria $(25$ $\left.\mu \mathrm{mol} . \mathrm{m}^{-2} \cdot \mathrm{s}^{-1}\right)$. A freqüência das repicagens foi mensal de forma à obter material vegetal suficiente para a instalação dos experimentos. Foram selecionadas plântulas com tamanho médio ao redor de $12 \mathrm{~cm}$ de altura.

Para o estabelecimento dos tratamentos, o meio de cultura líquido do tubo de ensaio de onde estavam sendo mantidas as plantas foi drenado por inversão cuidadosa do tubo e substituído por meio de cultura contendo os tratamentos: Ácido metiljasmônico $(50 \mu \mathrm{M}), \mathrm{NaCl}(30 \mathrm{mM})$, polietilenoglicol (PEG - 10\%), BION (Benzothiadiazole $0,1 \mu \mathrm{g} / 10 \mathrm{~mL}$ ), nitrogênio (o triplo da concentração de $\mathrm{N} \mathrm{da}$ formulação do meio MS), boro (o triplo da concentração de $B$ da formulação do meio MS), ácido salicílico (10 mM), 24epibrassinolídeo $(0,1 \mathrm{mM})$. As plântulas foram mantidas nas condiçōes acima descritas por 5 e 10 dias. Cada tratamento foi composto por 3 repetiçôes, utilizando um delineamento inteiramente casualizado.

Após 5 e 10 dias do estabelecimento dos experimentos, em algumas plântulas a parte aérea e a raiz foram separadas e pesadas, e determinou-se o conteúdo ( $\mathrm{mg} / \mathrm{g}$ de massa fresca) de ácido betulínico na parte aérea. Para a determinação do o conteúdo de quercetina, rutina e 1,5-diidroxixantona foram usadas outras plântulas, que foram coletadas inteiras, sem separação de parte aérea e raiz. A extração dos metabólitos secundários e sua quantificação foram feitas de acordo com Abreu et al. (2004).

\section{RESULTADOS E DISCUSSÃO}

Aos 10 dias de exposição aos diferentes tratamentos, todas as plântulas, com exceção do controle, apresentaram alguma alteração nas folhas: $\mathrm{NaCl}$ - necrose das folhas da base; PEG - murcha do ápice e amarelecimento das folhas da base; $3 \mathrm{xN}$ ápice necrosado em uma das repetiçôes; $3 \mathrm{xB}$ - amarelecimento das folhas da base e presença de antocianina na ponta das folhas; BION-amarelecimento das folhas da base e na base das folhas mais apicais; EBL - aparecimento de novas brotações partindo das gemas nodais; Ácido metiljasmônico - necrose da plântula a partir do ápice; Ácido salicílico - amarelecimento das folhas basais e senescência.

A análise de ácido betulínico foi feita na fração de diclorometano das amostras (Figura 2). De maneira geral, as plântulas controle apresentaram maiores teores de ácido betulínico que as plântulas que receberam algum tipo de suplementação no meio MS. Exceto o tratamento com ácido salicílico e $\mathrm{NaCl}$, todos os outros tratamentos, incluindo o controle, mostraram maior produção de ácido betulínico aos 10 dias quando comparado aos 5 dias. Também com a exceção do tratamento com ácido salicílico e PEG, todos os tratamentos mostraram redução de ácido betulínico aos 5 dias, com o nível aumentando aos 10 dias, mas ainda em níveis

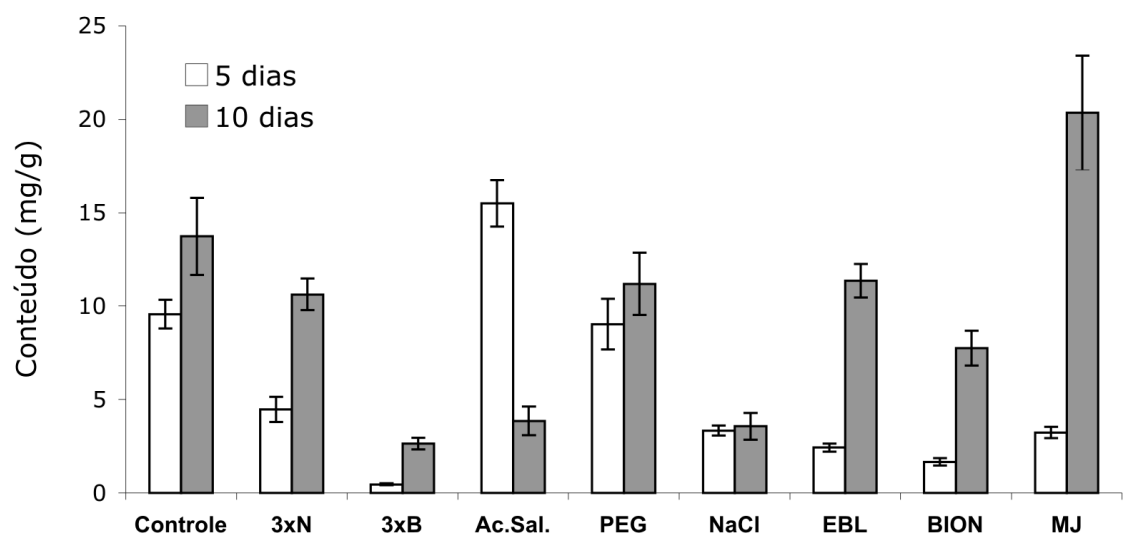

Figura 2 - Variação no conteúdo de ácido betulínico em plântulas de H. brasiliense crescendo in vitro, após 5 e 10 dias de exposição ao ácido salicílico, polietilenoglicol, 24-epibrassinolídeo, BION, metiljasmonato, NaCl, PEG e aumentadas concentricões de B e N (3 vezes a concentricão do meio MS). Médias de três repetições. Barras indicam os desvios padrão. 
inferiores ao controle ( $3 \mathrm{xB}, \mathrm{BION}, \mathrm{NaCl})$ ou no mesmo nível (3xN, PEG, EBL). No entanto, valores maiores que o controle nos dois dias avaliados foram apenas ácido salićlíco aos 5 dias e metiljasmonato aos 10 dias.

A análise dos compostos fenólicos presentes no extrato metanólico de $H$. brasiliense mostraram que para rutina, apenas o tratamento com PEG causou aumento no $5^{\circ}$ dia (Figura 3). Aos 10 dias, o tratamento de ácido salicílico também induziu maior produção desse fenol.

Quanto à quercetina, os tratamentos $3 \times \mathrm{N}, 3 \times \mathrm{B}$, ácido salicílico e PEG causaram o aumento de concentração aos 5 dias. No entanto, nenhum desses tratamentos persistiu com níveis altos aos 10 dias, sendo que nesta segunda avaliação, EBL e BION apresentaram os valores mais altos.

Os níveis de 1,5-diidroxixantona nos vários tratamentos ou permaneceram semelhantes aos do controle $(3 \mathrm{xN}, 3 \mathrm{xB}$, PEG), ou reduziram aos 5 dias. Porém, exceto metiljasmonato, todos apresentaram maiores concentraçôes do terpeno na avaliação de 10 dias.

Metiljasmonato é conhecido por ser um indutor da cascata do ácido octadecanóide com conseqüente expressão de genes relacionados à resistência a pragas e doenças (McConn et al., 1997; Thomma et al., 2000), como também induz a produção de compostos secundários (Walker et al., 2002; Yu et al., 2002). Ácido salicílico e seu análogo BION tem

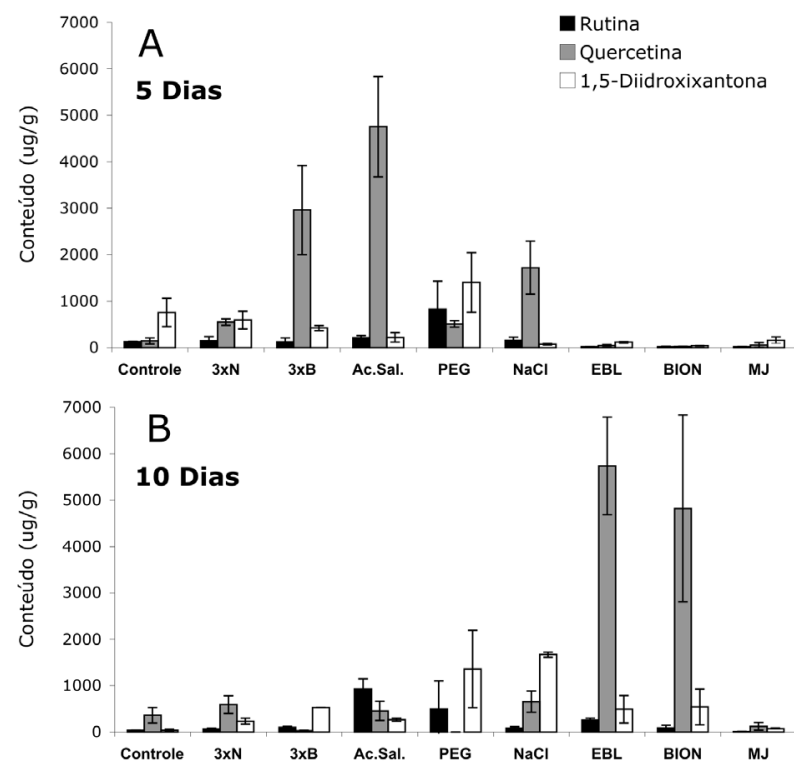

Figura 3 - Variação no conteúdo de rutina, quercetina e 1,5-diidroxixantona em plântulas de $H$. brasiliense crescendo in vitro, após 5 (A) e 10 (B) dias de exposição ao ácido salicílico, polietilenoglicol, 24-epibrassinolídeo, BION, metiljasmonato, $\mathrm{NaCl}$, PEG e aumentadas concentricões de $\mathrm{B}$ e $\mathrm{N}$ (3 vezes a concentricão do meio MS). Médias de três rpetições. Barras indicam os desvios padrão. sido amplamente estudados em relação aos mecanismos de sinalização em plantas e as respostas ao ataque de pragas e doenças (Hammerschmidt, 1999; Pozo et al., 2004; Fujita et al., 2006) o que provavelmente está relacionado à capacidade de afetarem o metabolismo secundário de plantas (Nugroho et al., 2002; Avancini et al., 2003).

Brassinoesteróides também são conhecidos por proteger plantas contra estresses hídrico e salino, alterando a expressão de vários genes (Zullo \& Adam, 2002; Nuñez et al., 2003/2004; Choe, 2006).

A literatura também tem mostrado que plantas acumulam compostos secundários em resposta a estresse salino (Brachet \& Cosson, 1983; Tramontano \& Jouve, 1997) e a estresse hídrico (Saenz et al., 1993). Também, variações acima ou abaixo do ótimo em relação a elementos essenciais tem mostrado influenciar fortemente o metabolismo de compostos secundários (Mazzafera, 1999).

$H$. perforatum possui hipericina e pseudohipericina, substâncias que reconhecidamente estão envolvidas no efeito anti-depressivo dessa espécie (Suzuki et al., 1984). Por esta característica, $H$. perforatum é a espécie mais estudada do gênero e alguns trabalhos mostraram que metiljasmonato, em diferentes concentraçôes, estimulou o acúmulo de xantonas, flavonóides, hipericina e hiperforina (Kirakosyan et al., 2000; Sirvent \& Gibson, 2002; Walker et al., 2002; Conceição et al., 2006), indicando que esta substância tem um importante papel na regulação do metabolismo secundário.

Apenas um trabalho estudou o controle da biossíntese de alguns compostos secundários em $H$. brasiliense. A imposição de estresses hídricos (falta e excesso) e de temperatura (baixa, e baixa alternada com alta) induziram significantes alteraçōes nos níveis de ácido betulínico, rutina, quercetina e diidroxixantona (Abreu e Mazzafera, 2005).

No presente trabalho se observou que as respostas diferem não só em relação aos tratamentos, mas também em função do tempo de tratamento. $\mathrm{O}$ melhor exemplo disso foi a variação no teor de quercetina nos tratamentos $3 \times \mathrm{xB}$ e ácido salicílico aos 5 dias, e EBL e BION aos 10 dias.

Rutina é formada a partir de quercetina pela ligação de um resíduo rutinosídeo (glicose-ramnose) à posição 3 da molécula (Barber \& Behrman, 1991). Desta forma, um aumento em quercetina poderia refletir interrupção da conversão a rutina. No entanto, a queda no conteúdo de quercetina em alguns tratamentos não se refletiu no aumento de rutina, sugerindo que a via é modulada diferentemente.

Xantonas, tal como 1,5-diihidroxixantona, são formadas no metabolismo do ácido chiquímico, assim como rutina e quercetina (Beerhues \& Berger, 1995; Vermerris \& Nicholson, 2006). No entanto, aqui não se observou variação no sentido de que o aumento de uma substância deve ser acompanhado do 
aumento de outras substâncias da mesma rota, mostrando que o controle do nível dessas substâncias são independentes.

Ácido salicílico, ácido metiljasmônico e BION são conhecidos indutores do metabolismo secundário e têm sido reportados como indutores na produção de substâncias de resposta de defesa das plantas, sendo isto muitas vezes relacionado ao aumento de substâncias do metabolismo secundário. Porém, o estresse causado pelo tratamento com ácido metiljasmônico não levou a aumentos relevantes nos níveis dos compostos fenólicos aqui estudados, mesmo para a xantona 1,5-diihidroxixantona, como já havia sido observado em Hypericum androsaemum (Beerhues \& Berger, 1995). Resultados com ácido metiljasmônico também já foram obtidos com suspensóes celulares e calos de $H$. perforatum cultivados no escuro, induzindo a produção de hipericina (Walker et al., 2002).

No presente estudo PEG foi usado para induzir estresse osmótico em plântulas, sendo observada redução do conteúdo apenas de quercetina entre os compostos estudados. O mesmo foi observado por Abreu \& Mazzafera (2005), que impuseram déficit hídrico em plantas adultas de $H$. brasiliense. Desta forma, plântulas crescendo in vitro poderiam ser usadas como modelos de estudo no controle da biossíntese dessas substências.

\section{AGRADECIMENTOS}

Os autores são gratos à Fundação de Amparo à Pesquisa do Estado de São Paulo (Fapesp) e Conselho Nacional de Desenvolvimento Científico e Tecnológico (CNPq) pelo fornecimento de bolsas de estudo (MALV, INA) e de pesquisador (PM) aos autores.

\section{BIBLIOGRAFIA CITADA}

Abreu, I.N.; Porto, A.L.M., Marsaioli, A.J.; Mazzafera, P. 2004. Distribution of bioactive substances from Hypericum brasiliense during plant growth. Plant Science, 167: 949-954.

Abreu, I.N.; Mazzafera, P. 2005. Effects of water and temperature stress of activity constituent Hypericum brasiliense Choisy. Plant Physiology and Biochemistry, 43:241-248.

Abreu, I.N. 2002. Isolamento e produção de substâncias de interesse farmacológico de Hypericum brasiliense Choisy. Tese de doutorado, Universidade Estadual de Campinas, Campinas, São Paulo.

Avancini, G.; Abreu, I.N.; Saldaña, M.D.A.; Mohamed, R.S.; Mazzafera P. 2003. Induction of pilocarpine formation in jaborandi leaves by salicylic acid and methyljasmonate. Phytochemistry, 63: 171-175.

Barber, G.A.; Behrman, E.J. 1991. The synthesis and characterization of uridine 5' -(beta-L-rhamnopyranosyl diphosphate) and it role in the enzymatic-synthesis of rutin. Archives of Biochemistry and Biophysics, 288: 239-242.
Beerhues, L.; Berger, U. 1995. Differential accumulation of xanthone in methyl jasmonate and yeast extract treated cell cultures of $C$. erythraea and C. littorale. Planta, 197:608-612.

Brachet, J.; Cosson, L. 1983. Changes in the total alkaloid content of Datura inoxia Mill. subjected to salt stress. Journal of Experimental Botany, 37: 650-656.

Cardoso, M.A.; Oliveira, D.E. 1996. Tissue culture of Hypericum brasiliense Choisy: Shoot multiplication and callus induction. Plant Cell Tissue and Organ Culture, 44:91-94.

Choe, S. 2006. Brassinosteroid biosynthesis and inactivation. Physiologia Plantarum, 126: 539-548

Conceição, L.R.F.; Ferreres, F.; Tavares, R.M. 2006. Induction of phenolic compounds in Hypericum perforatum L. cells by Colletotrichum gloesporioides elicitation. Phytochemistry, 67:149155.

Croteau, R.; Kutchan, T.M.; Lewis, N.G. 2000. Natural products (Secondary metabolites). In: Buchanan, B.; Gruissem, W.; Jones, R. (Ed.). Biochemistry and Molecular Biology of Plants. American Society of Plant Physiologists, Rockville. p. 1250-1318.

Dixon, R.A.; Paiva, N. 1995. Stress-induced phenylpropanoid metabolism. Plant Cell; 7:1085-1097.

Fujita, M.; Fujita, Y.; Noutoshi, Y.; Takahashi, F.; Narusaka, Y.; Yamaguchi-Shinozaki, K.; Shinozaki, K. 2006. Crosstalk between abiotic and biotic stress responses: a current view from the points of convergence in the stress signaling networks. Current Opinion in Plant Biology, 9: 436-442.

Hammerschmidt, R. 1999. Induced disease resistance: how do induced plants stop pathogens? Physiological and Molecular Plant Pathology, 55: 77-84.

Kirakosyan, A.; Hayashi, H.; Inoue, K.; Charchoglyan, A. ; Vardapetyan, H. 2000. Stimulation of the production of hypericins by mannan in Hypericum perforatum shoot cultures. Phytochemistry, 53: 345-348.

Mazzafera, P. 1999. Mineral nutrition and caffeine content in coffee leaves. Bragantia, 58: 387-391.

McConn, M., Creelman, R.A.; Bell, E.; Mullet, J.E.; Browse, J. 1997. Jasmonate is essential for insect defense in Arabidopsis. Proceedings of the National Academy of Science USA, 94: 5473-5477.

Nuñez, M.; Mazzafera, P.; Mazorra, L.M.; Siqueira, W.J.; Zullo, M.A.T. 2003/2004. Influence of a brassinosteroid analogue on antioxidant enzymes in rice growing in culture medium with NaCl. Biologia Plantarum, 47: 67-70.

Murashige,T.; Skoog, F. 1962. A revised medium for rapid growth and bioassays with tobacco tissue culture. Plant Physiology, 15: 473-497.

Nugroho, L.H.; Verberne, M.C.; Verpoorte, R. 2002. Activities of enzymes involved in the phenylpropanoid pathway in constitutively salicylic acid-producing tobacco plants. Plant Physiology Biochemistry, 40: 755-760

Oliveira, B.H.; Santos, Cid. A.M.; Espíndola, A.P.D.M. 2002. Determination of the triterpenoid, betulinic acid, in Doliocarpus schottianus by HPLC. Phytochemical Analysis, 13:95-98. 
Pasqua, G.; Avato, P.; Monacelli, B.; Santamaría, AR.; Argentieri, M.P. 2003. Metabolites in cell suspension cultures, calli, and in vitro regenerated organs of Hypericum perforatum cv. Topas. Plant Science, 165: 977-982.

Pozo, M.J.; Loon, L.C.V.; Pieterse, C.M.J. 2004. Signals in plantmicrobe interactions Journal of Plant Growth Regulation, 23: 211-222;

Rocha, L.; Marston, A.; Kaplan, M.; Stoecklievans, H.; Thull, U.; Testa, B.; Hostettmann, K. 1994. An antifungal $\gamma$-pyrone and xanthones with monoamine oxidase inhibitory activity from Hypericum brasiliense. Phytochemistry, 36: 1381-1385.

Rocha, L.; Marston, A.; Potterat, O.; Kaplan, M.; Evans, H.; Hostettmann, K. 1995. Antibacterial phloroglucinols and flavonoid from Hypericum brasiliense. Phytochemistry, 40: 1447-1452.

Rocha, L.; Marston, A.; Potterat, O.; Kaplan, M.; Hostettmann, K. 1996. More phoroglucinols from Hypericum brasiliense. Phytochemistry, 42: 185-188.

Saenz, L.; Santamaría, J.M.; Villanueva, M.A.; Loyola-Vargas, V.M.; Oropeza, C. 1993. Changes in the alkaloid content of plants of Catharanthus roseus L. (Don). as a result of water stress and treatment with abscisic acid. Journal of Plant Physiology, 142: 244-247.

Sirvent, T.; Gibson, D. 2002. Induction of hypericins and hyperforin in Hypericum perforatum L. in response to biotic and chemical elicitors. Physiological and Molecular Plant Pathology, 60: 311320 .

Suzuki, O.; Katsumata, Y.; Oya, M. 1984. Inhibition of monoamine oxidase by hypericin. Planta Medica, 50: 272-274.

Thomma, B.P.H.J.; Eggermont, K.; Broekaert, W.F.; Cammue, B.P.A. 2000. Disease development of several fungi on Arabdopsis can be reduced by treatment with methyl jasmonate. Plant Physiology Biochemistry, 38: 421-427.
Tramontano, W.A.; Jouve, D. 1997. Trigonelline accumulation in salt-stressed legumes and the role of other osmoregulators as cell cycle control agents. Phytochemistry, 44: 1037-1040.

Vermerris, W.; Nicholson, R. 2006. Phenolic compound biochemistry.Springer, Dordrecht. 276 pp.

Verpoorte, R.; van der Heijden, R.; ten Hoopen, H.J.G.; Memelink, J. 1999. Metabolic engineering of plant secondary metabolite pathways for the production of fine chemicals. Biotechnology Letters, 21: 467-479.

Walker, T.S.; Bais, H.P.; Vivanco, J.M. 2002. . Phytochemistry, 60(3):289-293.

Yu, K.W.; Gao, W.Y.; Hahn, E.J.; Paek, K.Y. 2002. Jasmonic acid improves ginsenoside accumulation in adventitious root culture of Panax ginseng CA Meyer. Biochemical Engineering Journal, 11: 211-215

Zenk, M.H.; El Shagi, H.; Arens, H.; Stockigt, J.; Weiler, E.W.; Deus, B. 1977. In: Bars, W.; Reinhard, E.; Zenk, M.H. (Eds). Plant Tissue culture and its bio-technological application. SpringerVerlag, Berlin-Heidelberg. p.27-47.

Zobayed, S.M.A.; Murch, S.J.; Rupasinghe, H.P.V.; Saxena, P.K. 2004. In vitro production and chemical characterization of St. John's wort (Hypericum perforatum L. cv 'New Stem'). Plant Science, 166: 333-340

Zullo, M.A.T.; Adam, G. 2002. Brassinosteroid phytohormones structure, bioactivity and applications. Brazilian Journal of Plant Physiology, 14: 143-181.

Recebido em 10/03/2008

Aceito em 20/01/2009 